DOI 10.24144/2077-6594.4.2019.193548

УДК 614.253.5:725.51

Баркаси Д.

\title{
Просоциальные тенденции медсестер, работающих в больнице
}

Медицинский университет здравоохранения и социальной работы св. Алжбеты, н.о, филиал бл. Метода Доминика Трчку, Братислава, Словакия

daniela.barkasi@gmail.com

\author{
Баркасі Д. \\ Просоціальні тенденції медсестер, \\ що працюють у лікарні \\ Медичний університет охорони здоров'я \\ і соціальної роботи св. Алжбети, н.о., \\ філія бл. Методу Домініка Трчку, Братислава
}

\author{
Barkasi D. \\ Prosocial tendencies of nurses \\ working in hospital facilities \\ Medical University of Health \\ and Social Work Algeria, n.o., \\ branch of bl. Methods of Dominic Trchku, Bratislava
}

\section{Введение}

Область просоциальных тенденций является одним из предметом исследования психологии. Она уделяет достаточно большое внимания волонтерству [1], а в области помогающих профессий - подготовке к будущей специальности [2], авторы провели исследование на отобранных студентах университетов, обучающихся по специальностям: социальный работник и сестринское дело, они наблюдали просоциальные тенденции в мотивации к учебе и социальной поддержке. [3] Исследования просоциальных тенденции проводились между студентами сестринского дела, [4] изучалась взаимосвязь между выбранными характеристиками личности и мотивацией к обучению сестринскому делу. Они также изучали просоциальное поведение среди старшеклассников и студентов $[5,6]$ и возникновение просоциального поведения у выбранной группы студентов-медсестер и практикующих медсестер. Просоциальное поведение, или „добровольное поведение, призванное приносить пользу другому человеку“ - это форма гражданского участия, которая осуществляется добровольно на благо широкой общецтвенности без расчета на денежное вознаграждение. [7] Различают шесть типов просоциального поведения. Их разделение заключается в мотиве, который ведет помогающего человека к процессу помощи, и это следующие типы: альтруистическое, анонимное, запрошенное, эмоциональное, публичное и просоциальное поведение в условиях кризиса. Просоциальные тенденции - это внутренняя мотивационная готовность к такому типу поведения, то есть они выражают готовность человека вести себя просоциальным образом. Они были исследованы не только на выбанной группе студентов университетов, изучающих области помогающих профессий, но и на группе работающих профессионалов, а именно: социальных работников, которые работают на бирже труда с целевой группой безработных.

В этой статье мы сосредоточились на выявлении просоциальных тенденций у медсестер, работающих в больнице.

\section{Цель исследования}

Профессия медсестры - это помогающая профессия, которая требует профессиональных теоретических знаний, практических навыков, достигнутых университетским образованием, но помимо этого им также необходимы определенные личные качества, чтобы помочь хорошо выполнять свою работу. Такие характеристики личности включают в себя просоциальность. Мы считаем, что только просоциально ориентированный работник имеет этический подход к пациенту. В нашей статье мы сосредоточились на выявлении просоциальных тенденций у медсестер, работающих в больнице, с точки зрения возраста и отделения на котором они работают.

В исследовании были определены две гипотезы:

Гипотеза 1: Просоциальные тенденции медсестер варьируются в зависимости от их возраста.

Гипотеза 2: Просоциальные тенденции медсестер, работающих в хирургических отделениях, отличаются от просоциальных тенденций медсестер, работающих в терапевтических отделениях.

\section{Предмет и методы исследования}

Группа исследуемых состояла из 169 медсестер, работающих в хирургических и терапевтических отделениях. Возраст медсестер составлял от 23 до 62 лет, средний возраст 43,01 года. Цель исследования состояла в том, чтобы проверить влияние возраста на просоциальные тенденции медсестер в отдельных измерениях, а также 
проверить связь между просоциальными тенденциями медсестер и типом отделения, в которым они работают В качестве инструмента исследования мы использовали опросник, первая часть которого содержала 4 демографических вопроса, а вторая часть содержала 23 пункта и была взята у автора [1], который следил за проверкой психометрических свойств методологии измерения просоциального поведения. Шкала ответов на отдельные вопросы типа Ликертовского была 5-уровевой. Вторая часть анкеты включала шесть типов просоциальных тенденций (отдельные элементы классифицируются по типам просоциальных тенденций).

\section{Обработка данных}

Для проверки гипотез мы использовали непараметрический тест Манна-Уитни и тест Спирмана

\section{Результаты исследований}

Гипотеза 1: Просоциальные тенденции медсестер варьируются в зависимости от их возраста.

Поскольку просоциальные тенденции были исследованы в 6 областях, мы проверим в общей сложности 6 субгипотез. Для проверки гипотез мы использовали непараметрический тип коэффициента коэффициент Спирмана.

Как видно из таблицы 1, значительная связь была подтверждена в 4 типах просоциальных тенденций. Мы обнаружили связь с возрастом в просоциальных тенденциях в условиях кризиса. Столь же значимой является связь возраста с запрашиваемым типом просоциальных тенденций, эмоциональных просоциальных тенденций и анонимных просоциальных тенденций. Значения Р в этих типах просоциальных тенденций ниже, чем выбранный уровень значимости 0,01, то есть эти отношения статистически значимы. С другой стороны, ни связь с альтруистическим типом просоциальных тенденций, ни публичный тип просоциальных тенденций не подтвердились. Таким образом, мы заключаем, что альтруистический и публичный тип просоциальных тенденций не соотносится с возрастом.

Заключение гипотезы 1: гипотеза была подтверждена в 4 типах просоциальных тенденций из шести исследованных. Мы обнаружили, что возраст в значительной степени коррелирует с тенденциями в отношении запрашиваемого, эмоционального, анонимного просоциального или кризисного поведения. Связь между возрастом и альтруистическими или общественными просоциальными тенденциями не была подтверждена.

Таблица 1. Связь между возрастом и типом просоциальных тенденций

\begin{tabular}{|l|c|c|c|c|c|c|}
\hline Bозраст & Altruism $-\mathbf{R}$ & Compliance & Emotional & Public & Anonymous & Dire \\
\hline Spearman rho & 0,070 & $\mathbf{0 , 3 4 2}$ & $\mathbf{0 , 2 7 1}$ & $-0,043$ & $\mathbf{0 , 1 9 7}$ & $\mathbf{0 , 3 8 0}$ \\
\hline P-value & 0,369 & $0,000^{*}$ & $0,000^{*}$ & 0,581 & $0,010^{*}$ & $0,000^{*}$ \\
\hline
\end{tabular}

Таблица 2. Тип просоциальных тенденций по месту работы

\begin{tabular}{|l|l|l|l|l|l|l|l|}
\hline \multicolumn{1}{|c|}{ Тип тенденции } & \multicolumn{1}{|c|}{ Рабочее место } & $\mathbf{N}$ & Mean & StDev & Median & U stat & P-Value \\
\hline Altruism & внутренний & 81 & 1,57 & 0,5652 & 1,50 & 6859 & 0,936 \\
\hline \multirow{2}{*}{ Compliance } & хирургический & 88 & 1,66 & 0,7181 & 1,50 & & \\
& внутренний & 81 & 4,29 & 0,6995 & 4,50 & 7067 & 0,568 \\
\hline \multirow{2}{*}{ Emotional } & хирургический & 88 & 4,33 & 0,4651 & 4,50 & & \\
& внутренний & 81 & 3,04 & 0,7859 & 3,00 & 6576 & 0,332 \\
\hline \multirow{2}{*}{ Public } & хирургический & 88 & 3,13 & 0,5888 & 3,20 & & \\
\hline \multirow{2}{*}{ Anonymous } & внутренний & 81 & 2,27 & 0,7943 & 2,00 & 6653 & 0,466 \\
\hline \multirow{2}{*}{ Dire } & хирургический & 88 & 2,34 & 0,8311 & 2,33 & & \\
\hline & внутренний & 81 & 3,15 & 1,129 & 3,25 & 6711 & 0,585 \\
\hline & хирургический & 88 & 3,27 & 0,9012 & 3,25 & & \\
\hline
\end{tabular}

Гипотеза 2: Просоциальные тенденции медсестер, работающих в хирургических отделениях, отличаются от просоциальных тенденций медсестер, работающих в терапевтических отделениях.

Как видно из таблицы 2, все значения Р находятся выше уровня значимости. Поэтому отдельные типы просоциальных тенденций не отличаются в исследуемых группах, и обнаруженные небольшие различия могут быть вызваны случайными эффектами.

Заключение гипотезы 2: Мы заключаем, что гипотеза 2 не была подтверждена ни в одной из субгипотез. Мы обнаружили, что просоциальные поведенческие тенденции медсестер не связаны с типом рабочего места. Эти поведенческие тенденции одинаковы для медсестер в хирургическом и терапевтическом отделениях. 


\section{Обсуждение}

Просоциальное поведение - или ,добровольное поведение, призванное приносить пользу другому человеку“ - это форма гражданского участия, которая осуществляется добровольно на благо широкой общецтвенности без расчета на денежное вознаграждение. В нашем исследовании мы россматривали просоциальное поведение у медсестер, работающих в хирургическом и терапевтическом отделениях. Мы нашли связь между возрастом и просоциальными тенденциями в условиях кризиса. Аналогично значимая связь с возрастом была обнаружена с запрашиваемым типом просоциальных тенденций, эмоциональных просоциальных тенденций и анонимных просоциальных тенденций. Просоциальное поведение в чрезвычайных ситуациях относится к оказанию помощи людям в кризисных или других экстремальных ситуациях, где необходимо немедленное и быстрое вмешательство [8].

С другой стороны, мы не подтвердили связь возраста с альтруистическим типом просоциальных тенденций или с публичным типом просоциальных тенденций поведения. Мы сравнили результаты нашего исследования с исследованием авторов [3], которые заметили различия в трех типах просоциальных тенденций с точки зрения возраста среди студентов. При анонимном и альтруистическом типе просоциальной тенденции старшая группа студентов достигла более высоких, статистически значимых, средних значений. Этот вывод не идентичен с нашим, мы обнаружили наибольшую зависимость с возрастом в просоциальных тенденциях в критических ситуациях и значительную зависимость возраста с запрашиваемым типом просоциальных тенденций. Запрашиваемое просоциальное поведение означает помогать другим, что является спонтанным поведением, мотивированным вербальным или невербальным запросом. Этот вид просоциального поведения чаще встречается среди людей, чем спонтанная помощь [8]. Далее авторы сообщают, что по двум типам просоциальных тенденций они обнаружили статистически значимое различие и более высокие средние значения в возрастной и самой старшей группе. Это был желаемый тип просоциальных тенденций и просоциальных тенденций в критических ситуациях. Этот результат также подтверждается нашим выводом о том, что более высокая взаимосвязь с возрастом наблюдается в критических ситуациях при просоциальном поведении и при запрашиваемом просоциальном поведении. Авторы также отметили, что самая младшая возрастная группа студентов в возрасте от 19 до 35 лет имела более высокие средние значения в публичном типе просоциальной тенденции. Это также согласуется с результатами нашего исследования, где мы не подтвердили связь между альтруистическим и публичным просоциальным поведением с возрастом. Склонность к такому поведению уменьшается с возрастом. Как указано [1], возраст тесно связан с различными типами просоциального поведения. Мы также подтвердили это нашим исследованием, которое показало, что возраст напрямую взаимосвязан c тенденциями в отношении запрашиваемого эмоционального, анонимного просоциального и критического поведения. Связь между возрастом и альтруистическим или публичным просоциальным поведением не подтверждена.

Просоциальное поведение развивается постепенно по мере взросления личности, когнитивных и аффективных компонентов ее составляющиг, которые могут развиваться или изменяться в ходе практики в положительном, но также и отрицательном направлении и влиять на работу медсестер [6].

Во второй гипотезе мы сосредоточились на сравнении просоциальных тенденций медсестер, работающих в хирургических и терапевтических отделениях. Просоциальная личность - это тот, кто обладает чубством сострадания к другим людям, у которых есть проблемы и заботы. Он без зависти воспринимает чужие достижения, понимает текущее эмоциональное состояние другого человека. Альтруист - это человек, который бескорыстно заботится о благополучии других $[9,10]$. Эти качества должны быть присущи каждой медсестре. Мы предпологали, что медсестры будут статистически значимо различаться по распространенному типу просоциальных тенденций в отношении отделени, в которых они работают. Медсестры, работающие в хирургическом и терапевтическом отделениях, были включены в исследование, и характеристики двух групп были сопоставлены с помощью статистических тестов. Мы обнаружили, что средние значения в отдельных типах просоциальных тенденций не различались в исследуемых группах, а небольшие обнаруженные различия, вероятно, были вызваны случайными эффектами. Поскольку мы не нашли аналогичных исследований в специализированной литературе которая занимается данной проблемой, мы не приводим сравнение. Мы пришли к выводу, что гипотеза не была подтверждена ни в одной из субгипотез. Мы обнаружили, что просоциальные поведенческие тенденции медсестер не связаны с типом рабочего места (отделения). Эти поведенческие тенденции одинаковы для медсестер в хирургическом и терапевтическом отделениях.

Основываясь на наших результатах, мы предлагаем поддержать и мотивировать медсестер к просоциальному поведению в форме различных образовательных программ, курсов, семинаров. Развивать всестороннюю просоциальность в начальных и средних школах, например, в форме волонтерской деятельности а также включить предмет «Социально-психологический тренинг направленный на просоциальное поведение» в программу обучения медсестер. Автор [11] утверждает, что просоциальное поведение студентов в области социальной работы в значительной степени поддерживается волонтерством в начальных и средних школах, то есть еще до начала обучения в университете по данной специальности.

\section{Перспективы дальнейших исследований}

Отслеживаемая проблема очень интересна, её исследование необходимо с точки зрения важности личного роста медсестер. С точки зрения дальнейших 
исследований было бы интересно наблюдать просоциальные тенденции с точки зрения других социально-демографических характеристик (например, пол, уровень образования, член семьи - медицинский работник), а также других переменных (например, стаж работы). Было бы также интересно исследовать взаимосвязь между просоциальными тенденциями и мотивами становления медсестры, эмпатией, религиозностью, личностными характеристиками с точки зрения 5-факторного анализа и социальной поддержки.

\section{Выводы}

В нашем исследовании мы обнаружили, что с увеличением возраста медсестер возрастает тенденция помогать другим людям в чрезвычайных или кризисных ситуациях. Кроме того, мы обнаружили, что просоциальные тенденции в поведении медсестер не связаны с типом рабочего места, в терапевтическом и хирургическом отделениях. Важно обращать внимание на просоциальность во время процесса обучения. Благодаря профессиональной практике отдельные типы просоциальных тенденций могут меняться как в позитивном, так и в негативном плане, что также может влиять на работу медсестры. Уже во время учебы и практики, необходимо поддерживать чувство ответственности и сочувствия медсестер, организовывать различные образовательные программы, ориентированные на просоциальное поведение. Было бы целесообразно организовать учебные программы, которые будут направлены на обучение медсестер защитным механизмам, охранив их при этом от нежелательных последствий негативных эмоций от контакта с человеком, которые могут увеличить вероятность просоциального поведения медсестры. [12] утверждают, что профессия медсестры является вызовом, в котором есть желание профессионально заботиться о нуждающихся. Для достижения этой цели медсестрам необходимы не только мотивация, стимулы, но и личные предпосылки просоциальность - являются важным элементом.

Тема интересная и необходимая, потому что только медсестра, которая приобрела профессиональные знания, навыки и просоциальность, является действительно помогающим профессионалом.

\section{Література}

1. Babinčák, P. 2011. Prosocial Tendencies Maesure - Revised (PTM-R) - prvá skúsenost's krátkou metodikou na meranie prosociálneho správania. Sociální procesy a osobnost. Člověk na cestě zivotem: Křižovatky a mosty Kroměříž 14-16. 9.2011. Sborník př́ispěvků Conference Proceedings Psychologický ústav Filozofické fakulty Masarykovy univerzity, Brno. Tribun EU, 2011. ISBN 978-80-263-0029-8, s. 7-12.

2. Barkasi, D. - Leczová, D. 2019. Motivácia k vol’be študijného odboru študentov pomáhajúcich profesií. 1. vyd. Michalovce : Vysoká škola zdravotníctva a sociálnej práce sv. Alžbety, n. o. v Bratislave, Ústav bl. Metoda Dominika Trčku v Michalovciach, 2019. 90 s. ISBN: 978-80-8132-210-5.

3. Barkasi, D. Vansač, P. 2019. Prosociálne tendencie študentov v študijnom odbore Ošetrovatel'stvo. In Cesta k modernímu ošetřovatetelství XIX. Sborník př́íspevků a abstrakt z odborné konference s medzinárodní účastí. Praha : Fakultní nemocnice v Motole, 2019. ISBN: 978-80-87347-41-6, s. 147-154.

4. Leczová, D. Barkasi, D. Lachytová, L. 2017. Vybrané osobnostné charakteristiky vysokoškolákov vo vzt’ahu k ich motivácií pri vol'be študijného odboru Ošetrovatel'stvo. In. Cesta k modernímu ošetřovatetelství XIX. Sborník příspevků a abstrakt z odborné konference s medzinárodní účastí. Praha : Fakultní nemecnice v Motole, 2017. ISBN: 978-80-87347-37-9, s. $36-43$.

5. Mlčák, Z. 2010. Prosociální chování v kontextu dispozičných aspektů osobnosti. 1. vyd. Ostrava : Ostravská univerzita v Ostrave, 2010. 237 s. ISBN 978-80-7368-857-8.

6. Bánovčinová, L. Bubeniková, M. 2011. Prosociálne správanie a ošetrovatel'stvo. In Kontakt. ISSN 1212-4117, 2011, $13 / 2$, s. $148-156$.

7. Carlo, G. Randall, B. A. 2002. The developmentof a measure of prosocial behaviors for late adolescents. In Journal of Youth and Adolescence, 2002,vol. 31, no 1, s. $31-44$.

8. Záškodná, H. MLČÁK, Z. 2009. Osobnostní aspekty prosociálního chování a empatie. 1. vyd. Praha : Triton, 2009. 392 s. ISBN 978-80-7387-306-6.

9. Vansač, P. 2011. Vybrané kapitoly z etiky. 1. Vyd. Prešov : Ústav sociálnych vied a zdravotníctva bl. P.P. Gojdiča v Prešove, 2011. 128. ISBN: 978-80-8132-030-9.

10. Belovičová, M. Vansač, P. 2019. Selected aspects of medical and social care for long-term ill persons. Towarzystwo Slowakow w Polsce. Krakow 2019, 153 s., ISBN: 978-83-8111-109-6.

11. Nová, M. 2016. Edukace v kontextu nových fenoménů společnosti - sociální a edukační aspekt. In Nová sociálna edukácia človeka V. recenzovaný zborník z medzinárodnej vedeckej konferencie. Prešov: Prešovská univerzita v Prešove, 2016. s. 128 - 132. ISBN 978-80-555-1742-1.

12. Popovičová, M. Vansač, P. Pristášová, K. 2017. Motivácia sestier k autonómnej ošetrovatel'skej praxi. In MEDSTAT 2017. Monografia s tematickým zameraním na medicínsku štatistiku. Ružomberok : MedStat o.z. 2017. s 133146. ISBN 978-80-972293-1-3. 


\section{References}

1. Babinchak, R. 2011. Prosocialnye tendencii - peresmotren (PTM-R) - pervyj opyt s kratkoj metodologiej dlya izmereniya prosocialnogo povedeniya. Socialnye processy i lichnost. Chelovek na zhiznennom puti: perekrestok $\mathrm{i}$ mosty Kromerizh 14. -16. 9. 2011. Sbornik statej Materialy konferencii Institut psihologii fakultet filosofii universitet Masarika, Brno. Tribun ES, 2011. ISBN 978-80-263-0029-8, s. 7-12.

2. Barkasi, D. Leczova, D. 2019. Motivaciya k vyboru uchebnoj vetvi studentov, pomogayushih professiyam. 1. vyd. Mihalovce: Universitet zdravoohraneniya i socialnoj raboty sv. Elizavety, n. o. v Bratislave, Institut Bl. Metod Dominika Trchku v Mihalovcah, 2019. 90 s. ISBN: 978-80-8132-210-5.

3. Barkasi, D. Vansach, P. 2019. Prosocialnye tendencii studentov v oblasti obucheniya Sestrinskoe delo. Na puti k sovremennomu sestrinskomu delu XIX. Materialy i tezisy konferencii s mezhdunarodnym uchastiem. Praga: klinika v Motole, 2019. ISBN: 978-80-87347-41-6, s. 147-154.

4. Leczova, D. Barkasi, D. Lahitova, L. 2017. Izbrannye lichnostnye harakteristiki studentov vuzov v svyazi s ih motivaciej pri vybore fakulteta Sestrinskoe delo. Put k sovremennomu sestrinskomu delu XIX. Materialy i tezisy konferencii s mezhdunarodnym uchastiem. Praga: bolnica v Motole, 2017. ISBN: 978-80-87347-37-9, s. 36-43.

5. Mlchak, Z. 2010. Prosocialnoe povedenie v kontekste dispozicionnyh aspektov lichnosti. 1. vyd. Ostrava: Ostravskij universitet v Ostrave, 2010. 237 s. ISBN 978-80-7368-857-8.

6. Banovchinova, L. Bubenikova, M. 2011. Prosocialnoe povedenie i sestrinskoe delo. V kontakt. ISSN 1212-4117, 2011, 13/2, s. 148-156.

7. Karlo, G. Randall, V.A. 2002. Razrabotka mery prosocialnogo povedeniya dlya pozdnih podrostkov. V zhurnale molodezhi i podrostkov, 2002, tom. 31, № 1, s. 31-44.

8. Zashkodna, G. Mlchak, Z. 2009. Lichnostnye aspekty prosocialnogo povedeniya i empatii. 1. vyd. Praga: Triton, 2009. 392 s. ISBN 978-80-7387-306-6.

9. Vansach, P. 2011. Izbrannye glavy iz etiki. 1. vyd. Preshov: Institut socialnyh nauk i zdravoohraneniya bl. P. P. Gojdicha v Preshove, 2011. 128. ISBN: 978-80-8132-030-9.

10. Belovichova, M. Vansach, S. 2019. Otdelnye aspekty mediko-socialnoj pomoshi dlya dlitelno bolnyh lyudej. Tovarishestvo slovakov v Polshe . Krakov, 2019, 153 s., ISBN: 978-83-8111-109-6.

11. Nova, M. 2016. Obrazovanie v kontekste novyh yavlenij obshestva - socialno-obrazovatelnyj aspekt. V «Novoe socialnoe obrazovanie cheloveka» V. zbornik s mezhdunarodnoj nauchnoj konferencii. Preshov: Universitet Preshova, 2016. s. 128 - 132. ISBN 978-80-555-1742-1.

12. Popovichova, M. Vansach, P. Pristashova, K. 2017. Motivaciya medsester k praktike samostoyatelnogo uhoda. V MEDSTAT 2017. Monografiya posvyashena medicinskoj statistike. Ruzhomberok: MedStato.z. 2017. s 133-146. ISBN 978-80972293-1-3.

Дата надходження рукопису до редакції: 08.10.2019 р.

Цель исследования: целью представленного исследования было выявление просоциальных тенденций у медсестер, работающих в больнице, с точки зрения возраста и отделения, в котором они работают (хирургические и терапевтические отделения).

Методология исследования: исследование проводилось с помощью опросника, взятого у автора Бабинчак (2011), который был направлен на выявление просоциальных тенденций у медсестер и состоял из 23 пунктов, где ответы были 5-балльными по типу Лайкерта. Исследование проводилось на выборке из 169 медсестер, работающих в отделениях хирургии и терапии. Медсестрам было от 23 до 62 лет, средний возраст 43,01 года. Методология инструмента исследования основана на разделении просоциального поведения Карла и Рэндалла (2002), которые представляют шесть типов просоциального поведения.

Результаты: исследования показали, что с увеличением возраста, медсестры, как правило, более склонны помогать другим людям в чрезвычайных или кризисных ситуациях. Кроме того, мы обнаружили, что просоциальные тенденции в поведении медсестер не связаны с типом рабочего места, на котором они находятся (терапевтическое и хирургическое отделения).

Вывод: область просоциальных тенденций очень интересна и заслуживает повышенного внимания, потому что только медсестра, которая приобрела теоретические знания, практические навыки и обладает просоциальностью, является настоящим помогающим профессионалом.

Ключевые слова: просоциальные тенденции, медсестра, терапевтическое и хирургическое отделение, просоциальность, просоциальное поведение, пациент.

Мета дослідження: виявлення просоціальних тенденцій у медсестер, які працюють в лікарні, з точки зору віку і відділення, в якому вони працюють (хірургічні та терапевтичні відділення).

Методологія дослідження: дослідження проводилося за допомогою опитувальника, взятого у автора Бабінчак (2011), який був спрямований на виявлення просоціальних тенденцій у медсестер і складався з 23 пунктів, де відповіді 
були 5-бальними по типу Лайкерта. Дослідження проводилося на вибірці з 169 медсестер, які працюють у відділеннях хірургії та терапії. Медсестрам було від 23 до 62 років, середній вік 43,01 року. Методологія інструменту дослідження заснована на поділі про соціальної поведінки Карла і Рендалла (2002), які представляють шість типів просоціальної поведінки.

Результати: дослідження показали, що зі збільшенням віку, медсестри, як правило, більш схильні допомагати іншим людям в надзвичайних або кризових ситуаціях. Крім того, ми виявили, що просоціальні тенденції в поведінці медсестер не пов'язані з типом робочого місця, на якому вони знаходяться (терапевтичне та хірургічне відділення).

Висновок: область просоціальних тенденцій дуже цікава i заслуговує підвищеної уваги, тому що тільки медсестра, яка придбала теоретичні знання, практичні навички і володіє просоціальністю, є справжнім професіоналом.

Ключові слова: просоціальние тенденції, медсестра, терапевтичне і хірургічне відділення, просоціальність, просоціальна поведінка, пацієнт.

The object of research: the aim of the presented research was to identify prosocial tendencies in nurses working in a hospital facilities from the perspective of the age and the hospital ward in which they work (surgical and internal ward).

Research methods: we conducted the research by a questionnaire taken from the author Babinčák (2011), which was aimed at identifying prosocial tendencies in nurses and consisted of 23 items, where the responses were Likert type 5 - point. The research was carried out on a sample of 169 nurses working in the departments of surgery and internal medicine. The age of the nurses was between 23 and 62 years with an average age of 43.01 years. The methods of the research tool is based on the categorization of prosocial behavior by Carl and Randall (2002), who report six types of prosocial behavior.

Results: the research has shown that with increasing age, nurses have a stronger tendency to help other people in emergency or crisis situations. We also found that prosocial tendencies in nursing behavior are not related to the type of workplace they are working in within the examined departments - internal and surgical departments.

Conclusion: the area of prosocial tendencies is very interesting and deserves more attention, because only a nurse who has acquired the theoretical knowledge and displays prosocial behavior is a truly helping professional.

Key words: prosocial tendencies, nurse, internal and surgical department, prosociality, prosocial behavior, patient.

\section{Відомості про автора}

Баркаси Даниэла - д.б.н., доктор философии, Медицинский университет здравоохранения и социальной работы св. Алжбеты, н.о., Братислава, филиал бл. Метода Доминика Трчку; Партизанская 23, Михаловце, Словакия, 07101.

daniela.barkasi@gmail.com. 